\title{
Clinico-pathological Features and Outcome of Treatment of Saudi Patients with Oral Cavity Cancer: A Single Institutional Experience
}

\author{
Ashraf Farrag ${ }^{1,2^{*}}$, Arif Shaukat ${ }^{1}$, Muhammad Ali ${ }^{1}$ and Magdy Kandil ${ }^{1}$ \\ ${ }^{1}$ Department of Oncology, Prince Sultan Military Medical City, Riyadh, Kingdom of Saudi Arabia \\ ${ }^{2}$ Clinical Oncology Department, Assiut University, Assiut, Egypt
}

*Corresponding author: Ashraf Farrag, Department of Oncology, Prince Sultan Military Medical City, Assiut University, Riyadh, PO. Box 7897 Riyadh 11159, Kingdom of Saudi Arabia, Tel: +966563012513; +966508640381, E-mail: drashraffarrag@yahoo.com

\begin{abstract}
Background: This study presents the epidemiological data and clinico-pathological features of oral cancer in patients treated in Prince Sultan Military Medical City-Oncology Department over the last 7 years.

Methods: We reviewed all available data in our electronic and paper files for patients who had a confirmed pathological diagnosis of oral cavity malignancies between 2009-2015.

Results: A total of 87 patients with pathologically confirmed oral cancer. The majority of patients were males (M:F = 1.63:1). Median age at diagnosis was 62 years (24-95). History related to risk factors was completed in only 59 patients $(68 \%)$. Forty-five patients $(76 \%)$ had a positive history for tobacco usage either smoking and/or chewing (shamma). The use of shamma, (a mixture of powdered tobacco, lime, ash, black pepper, oils and flavorings), was confirmed in $31 / 59$ patients (either alone or associated with smoking). Oral Tongue as a primary site represents about half of the patients $44(50.6 \%)$, followed by alveolar ridge $(16.1 \%)$ and floor of mouth $(11.5 \%)$, buccal mucosa $(10.3 \%)$ and other sites $(11.5 \%)$. Two thirds of patients $(66.6 \%)$ presented with advanced stages (III and IV). The 5-year overall survival rates were $77.1 \%$ for the early stage disease group and $45.9 \%$ for the advanced stage disease group ( $P=0.028$ ) The 5-year progression-free survival rates were $65.6 \%$ for the early stage disease group compared with $28.1 \%$ for the advanced stage disease group $(P=0.02)$.
\end{abstract}

Conclusions: Most of our cases had a positive history of tobacco usage. This together with the high percentage of advanced diseases that carried a significantly poor outcome warrant the need for effective anti-tobacco campaigns, public awareness and primary care physicians education for early detection of disease.

\section{Keywords}

Epidemiology, Oral cancer, Clinicopathological features

\section{Introduction}

Oral cancer is the most common head and neck cancer (HNC). Its global incidence in 2015 was 410,000 cases with 146,000 deaths [1]. In USA, 41,380 patients were diagnosed with HNC in 2013 , and oral cavity cancers accounted for almost 30,000 of new cases [2]. In Saudi Arabia, a total number of 211 oral cancer cases were reported in 2014 , representing about $1.8 \%$ of the total cancer cases [3].

More than $90 \%$ of all oral cancers are squamous cell carcinoma (SCC) [4]. While around $10 \%$ consists of sarcomas, lymphomas, salivary gland tumors, melanomas, verrucous carcinomas, adenocarcinomas, adenoid cystic carcinomas, and mucoepidermoid carcinoma [2].

Unfortunately, the overall survival of oral cancer patients has not improved significantly during the past decade, with 5-year survival rates between $45-50 \%$ [5]. Early diagnosis is the most important factor for improving patient survival, rates as high as $80-90 \%$ on these first stages can be achieved. Early diagnosis also minimizes the extent of surgery required [4].

Oral cancers have different incidence rates in different areas of the world and different clinical and epidemiological features, which may be attributed to the difference in prevalence and patterns of exposure to risk factors. Tobacco smoking and chewing, alcohol consumption, and HPV infection are the major risk factors for oropharyngeal and oral cavity cancers, with tobacco and alcohol consumption having synergistic effects [6].

Several epidemiological studies on oral cancer were ment of Saudi Patients with Oral Cavity Cancer: A Single Institutional Experience. Int J Oncol Res 1:006. Accepted: July 26, 2018; Published: July 28, 2018

Copyright: (C) 2018 Farrag A, et al. This is an open-access article distributed under the terms of the Creative Commons Attribution License, which permits unrestricted use, distribution, and reproduction in any medium, provided the original author and source are credited. 
published in different countries. However, survival outcome of oral cancer in Saudi Arabia was addressed by few studies. The present study aimed to report the clinic-pathological features of our oral cavity cancer patients.

\section{Methods}

We reviewed all available data in our electronic and paper files for the patients who have a pathologically confirmed diagnosis of oral cavity malignancies between 2009-2015. Tumor stage was determined based on the 2010 American Joint Committee on Cancer (AJCC) TNM classification, $7^{\text {th }}$ edition [7].

\section{Treatment and follow up}

All patients were subjected to standard treatment protocols according to primary tumor site, stage and patient's general conditions. All cases were discussed in multidisciplinary ENT/Oncology combined clinic. After receiving primary treatment, patients are followed in the combined oncology and head and neck surgery clinic. Follow up visits are every 2 months for the $1^{\text {st }}$ year, every 3 months in the $2^{\text {nd }}$ year and every 4 months in the $3^{\text {rd }}$ year then every 6 months till completing 5 years, then annually. At each visit, patients are subjected to clinical examination. Radiological evaluations of response are usually performed in the first post-treatment visit by computed tomography (CT), Positron Emission Tomography (PET-CT) or Magnetic Resonance Imaging (MRI). Imaging studies are usually repeated if there is clinical suspicion for distant metastases and for restaging in the case of loco-regional recurrence. Local or regional recurrence must be confirmed pathologically.

\section{Statistical analysis}

Survival times were calculated from the day of diagnosis. Overall survival (OS) and progression free survival (PFS) were calculated at the date of death or relapse or the last date of follow up. Kaplan-Meier method was used for estimation of survival rates. The level of significance was set at $p \leq 0.05$.

\section{Results}

\section{Patient's characteristics}

A total of 87 patients had pathologically confirmed oral cancer. The majority of patients were males (M:F = 1.63:1). Median age at diagnosis was 62 years (24-95). Tongue cancer was the most common primary tumor site, 44 cases $(50.6 \%)$. Two thirds of patients presented with advanced stage; III and IV (66.6\%). The majority of cases were of squamous histology (91\%) (Table 1).

History related to risk factors was completed in only 59 patients (68\%). Forty-five patients $(76 \%)$ had a positive history for tobacco usage either smoking and/or chewing (shamma). The use of shamma was confirmed in 31/59 patients (either alone or associated with smoking). History of Shamma usage was relatively more common in females (63\%) vs. $49 \%$ in males. However, it was not statistically significant $(p=0.4)$.

\section{Treatment}

Forty-eight patients (55.2\%) had surgery either as a primary modality or after neoadjuvant treatment. Neoadjuvant chemotherapy (NACT) used for 25 patients (28.7\%) and concurrent chemo-radiotherapy (CCRT) used for 27 patients (31\%). Radical and postoperative radiotherapy (PORT) were used in $23(26.4 \%)$ and 32 (36.8\%) patients, respectively.

Table 1: Patients Characteristics.

\begin{tabular}{|c|c|c|c|}
\hline Characteristics & & $\begin{array}{l}\text { Numbers } \\
\text { (total }=87 \text { ) }\end{array}$ & Percentages \\
\hline Age & Median & $62(24-95)$ & \\
\hline \multirow[t]{2}{*}{ Sex } & $M$ & 54 & $62 \%$ \\
\hline & $\mathrm{F}$ & 33 & $38 \%$ \\
\hline \multirow[t]{3}{*}{ PS } & $<2$ & 56 & $64.4 \%$ \\
\hline & $\geq 2$ & 30 & $34.5 \%$ \\
\hline & Unknown & 1 & $1.1 \%$ \\
\hline \multirow[t]{6}{*}{ Residence } & Central & 26 & $29.9 \%$ \\
\hline & South & 32 & $36.8 \%$ \\
\hline & North & 8 & $9.2 \%$ \\
\hline & East & 3 & $3.4 \%$ \\
\hline & West & 1 & $1.1 \%$ \\
\hline & Non-Saudi & 17 & $19.5 \%$ \\
\hline \multirow[t]{6}{*}{ Habits } & $\begin{array}{l}\text { Smoking + } \\
\text { Shamma }\end{array}$ & 9 & $10.3 \%$ \\
\hline & Shamma only & 22 & $25.3 \%$ \\
\hline & Smoking only & 14 & $16.1 \%$ \\
\hline & Alcohol & 2 & $2.3 \%$ \\
\hline & Non & 14 & $16.1 \%$ \\
\hline & NA & 28 & $32.2 \%$ \\
\hline \multirow[t]{7}{*}{ Site } & Tongue & 44 & $50.6 \%$ \\
\hline & Palate & 4 & $4.6 \%$ \\
\hline & Alveolus & 14 & $16.1 \%$ \\
\hline & Buccal & 9 & $10.3 \%$ \\
\hline & Mouth floor & 10 & $11.5 \%$ \\
\hline & Lip & 4 & $4.6 \%$ \\
\hline & Retromolar & 2 & $2.3 \%$ \\
\hline \multirow[t]{3}{*}{ Histopathology } & SCC & 79 & $90.8 \%$ \\
\hline & Unknown & 2 & $2.3 \%$ \\
\hline & Others & 6 & $6.9 \%$ \\
\hline \multirow[t]{5}{*}{ Stage } & I & 10 & $11.5 \%$ \\
\hline & II & 15 & $17.2 \%$ \\
\hline & III & 15 & $17.2 \%$ \\
\hline & IV & 43 & $49.4 \%$ \\
\hline & $x$ & 4 & $4.6 \%$ \\
\hline \multicolumn{4}{|l|}{ Treatment } \\
\hline \multirow[t]{3}{*}{ Surgery } & Yes & 48 & $55.2 \%$ \\
\hline & NO & 38 & $43.7 \%$ \\
\hline & Unknown & 1 & $1.1 \%$ \\
\hline \multirow[t]{3}{*}{ Chemotherapy } & NACT & 25 & $28.7 \%$ \\
\hline & CCRT & 27 & $31.0 \%$ \\
\hline & No Chemo & 48 & $55 \%$ \\
\hline \multirow[t]{4}{*}{ Radiotherapy } & Radical & 23 & $26.4 \%$ \\
\hline & PORT & 32 & $36.8 \%$ \\
\hline & Palliative & 5 & $5.7 \%$ \\
\hline & No Radio & 27 & $31 \%$ \\
\hline
\end{tabular}

SCC: Squamous Cell Carcinoma; NACT: Neoadjuvant Chemotherapy; CCRT: Concurrent Chemoradiotherapy; PORT: Postoperative Radiotherapy; NA: Not Available. 


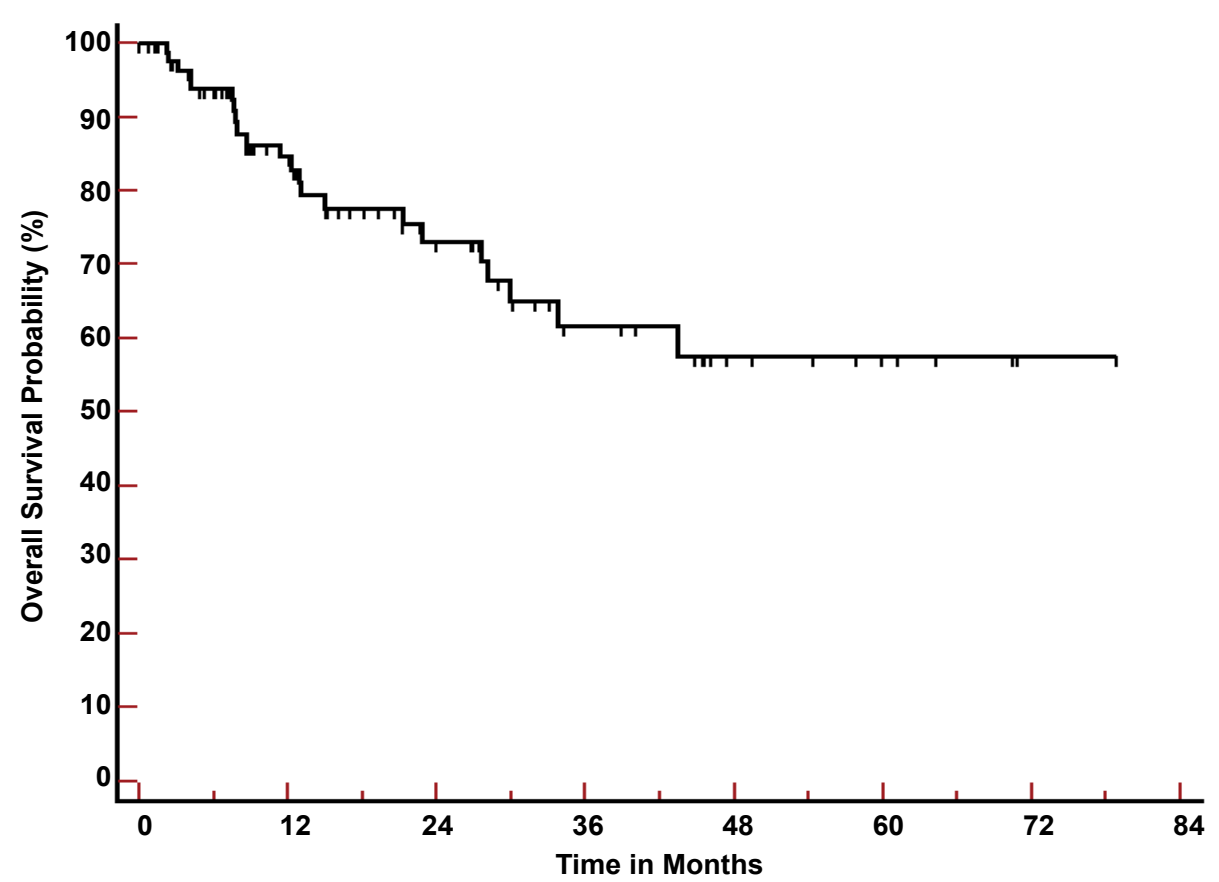

Figure 1: Overall Survival of 87 patients with oral cancer.

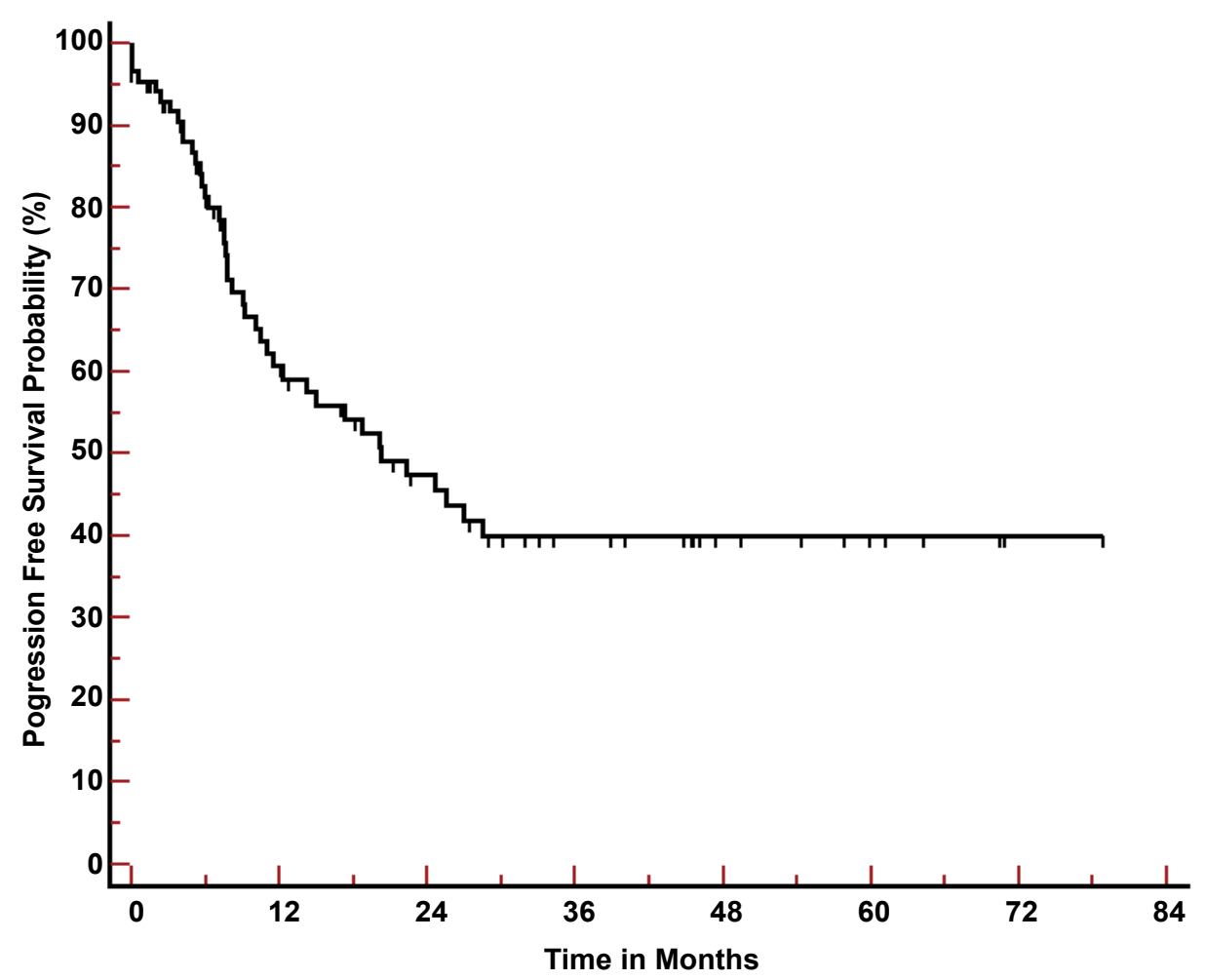

Figure 2: Progression free Survival of 87 patients with oral cancer.

\section{Survival outcomes}

Median follow up time was 15.63 months (1.3378.8). At the time of analysis, death was confirmed in 22 patients $(25.3 \%)$ and 41 patients had confirmed disease progression (47.2\%). The estimated OS and PFS at 5 years were $57.6 \%$ and $40 \%$, respectively (Figure 1 and Figure 2).

Table 2 shows that early stage at presentation together with the good performance status was associat- ed with better outcomes in term of both OS and PFS at 5 years.

\section{Discussion}

Despite the improvement in cancer management in the last decades, oral cancer still considered as a major health problem, associated with high incidence of morbidity and disfigurement. The advanced stage at presentation, in most cases, and the anatomical consideration further complicate the problem. 
Table 2: Survival outcome according to different prognostic factors.

\begin{tabular}{|c|c|c|c|}
\hline Variables & & 5-Y OS & 5-Y PFS \\
\hline \multirow[t]{3}{*}{ Age } & $<60$ & $57.2 \%$ & $43.7 \%$ \\
\hline & $\geq 60$ & $63.2 \%$ & $37.6 \%$ \\
\hline & & $P=0.3$ & $P=0.2$ \\
\hline \multirow[t]{3}{*}{ Sex } & $M$ & $60.8 \%$ & $43.0 \%$ \\
\hline & $\mathrm{F}$ & $54.4 \%$ & $35.9 \%$ \\
\hline & & $P=0.71$ & $P=0.36$ \\
\hline \multirow[t]{3}{*}{ ECOG PS } & $<2$ & $68.8 \%$ & $49.7 \%$ \\
\hline & $\geq 2$ & $41.6 \%$ & $23.4 \%$ \\
\hline & & $P=0.007$ & $P=0.028$ \\
\hline \multirow[t]{4}{*}{ Tobacco } & Yes & $60.7 \%$ & $33.7 \%$ \\
\hline & NO & $53.1 \%$ & $40.8 \%$ \\
\hline & N/A & $60.5 \%$ & $53.2 \%$ \\
\hline & & $P=0.75$ & $P=0.96$ \\
\hline \multirow[t]{3}{*}{ LN status } & Negative & $77.8 \%$ & $65.5 \%$ \\
\hline & Positive & $35.6 \%$ & $17.7 \%$ \\
\hline & & $P=0.0009$ & $P=0.0005$ \\
\hline \multirow[t]{3}{*}{ T-stage } & T1-T2 & $66.6 \%$ & $51 \%$ \\
\hline & T3-T4 & $48.2 \%$ & $30.6 \%$ \\
\hline & & $P=0.09$ & $P=0.22$ \\
\hline \multirow[t]{3}{*}{ Stage Group } & Early (I/II) & $77.1 \%$ & $65.6 \%$ \\
\hline & Advanced (III/IV) & $45.9 \%$ & $28.1 \%$ \\
\hline & & $P=0.028$ & $P=0.02$ \\
\hline
\end{tabular}

Ecog: Eastern Cooperative Oncology Group; Ps: Performance Status; Ln: Lymph Nodes.

In this study, tongue cancer represents more than half of the cases $(51 \%)$, which is consistent with most of the studies from western world [8-10]. Also, another study from Saudi Arabia showed $45 \%$ of oral cancer cases were of primary tongue origin [11]. In a recent review analysis of oral cancer in different Arab countries, tongue was the most common primary tumor site [12]. This is not the case among Asian populations. In a study from Pakistan, buccal cancer was found to be more common than tongue cancer ( $32 \%$ vs. $21.8 \%$, respectively) [13]. Also, in an Indian study tongue represented the primary tumor site in only $17 \%$ of the cases while buccal mucosa represented 35.5\% [14]. In addition, Researchers in Taiwan found that tongue cancer is the second most common oral cancer after buccal cancer [15]. This may be due to the different habits and exposure related to risk factors. Asian countries have varying patterns of use of tobacco and alcohol with the common use of betel quid/tobacco chewing [16].

A significant number of our patients are residents of the southern region where tobacco chewing (shamma) is a common habit. Shamma is a preparation of smokeless tobacco, being a mixture of powdered tobacco, carbonate of lime, ash, black pepper, oils and flavoring [17]. Shamma usage has been linked to the high frequency of oral cancer in the southwestern region of Saudi Arabia [18].

There is a clear defect in the history of special habits in our cases as it was deficient in about one third of patients. The percentage of shamma users was high (31/59) among patients with completed data; however, the real percentage of shamma users may be underestimated, as shamma is still illegal in Saudi Arabia. Similarly, alcohol is strictly prohibited, and this may explain why only two patients disclosed history of alcohol consumption.

In our cohort, M:F ratio (1.63:1) showed a higher proportion of female patients compared to the global statistics. The global M:F ratio is around 2:1 with some regional differences [19]. Some studies showed a much higher prevalence in male patients $[14,20]$. Additionally, in our study there is a significant minority of younger male patients. As mentioned above, a significant number of our patients were referred from the southern region of Saudi Arabia where shamma usage is common amongst both male and female individuals. Females, probably, start using shamma later in their lives. Smoking at young age may be the risk factor in the younger male population.

Two-thirds of our cases were presented in advanced stages. This is concordant with the findings in other studies in different geographical areas [12,13,20-22]. However, some studies, especially from the western world, showed a higher percentage of early diseases $[10,23,24]$. The burden of oral cancer is considered heavier in some developing countries, due to difficulties in primary prevention and application of regulatory policies, to access screening by a dental or medical professional and to have access to treatment when the disease has already progressed [25].

The 5 years survival outcomes in our patients are comparable to the global rates [16]. The stage at presentation was one of the most important factors for outcome at 5 years. Patients with early stage at presentation had better OS (77.1\% vs. $45.9 \%)$ and PFS (65.6\% vs. $28.1 \%$ ) compared to advanced stage group.

\section{Conclusion}

Most of our cases are presented in advanced stages, which reflected on the poor outcome. This warrants the need for increasing public awareness about the disease and for training of the primary health care professionals for early detection of premalignant conditions. Early referral to higher specialized centers ensues a higher opportunity for better management. The positive history of tobacco usage necessitates the need for effective anti-tobacco campaigns to enhance the public knowledge about tobacco induced deleterious effects.

\section{References}

1. Fitzmaurice C, Allen C, Barber RM, Barregard L, Bhutta ZA, et al. (2017) Global, regional, and national cancer incidence, mortality, years of life lost, years lived with disability, and disability-adjusted life-years for 32 cancer groups, 1990 to 2015: A systematic analysis for the global burden of disease study. JAMA Oncol 3: 524-548.

2. Ernani V, Saba NF (2015) Oral cavity cancer: Risk factors, pathology, and management. Oncology 89: 187-195. 
3. (2014) Cancer Incidence Report Saudi Arabia 2014.

4. Bagan J, Sarrion G, Jimenez Y (2010) Oral cancer: Clinical features. Oral Oncol 46: 414-417.

5. Omar EA (2013) The outline of prognosis and new advances in diagnosis of oral squamous cell carcinoma (OSCC): Review of the literature. Journal of Oral Oncology.

6. Shield KD, Ferlay J, Jemal A, Sankaranarayanan R, Chaturvedi AK, et al. (2017) The global incidence of lip, oral cavity, and pharyngeal cancers by subsite in 2012. CA Cancer J Clin 67: 51-64.

7. Edge SB, Byrd DR, Compton CC, Fritz AG, Greene FL, et al. (2010) AJCC cancer staging manual. ( $7^{\text {th }}$ edn), Springer, New York.

8. Lam L, Logan RM, Luke C (2006) Epidemiological analysis of tongue cancer in South Australia for the 24-year period, 1977-2001. Aust Dent J 51: 16-22.

9. Östman J, Anneroth G, Gustafsson H, Tavelin B (1995) Malignant oral tumours in Sweden 1960-1989-an epidemiological study. European Journal of Cancer Part B: Oral Oncology 31: 106-112.

10. Oliver AJ, Helfrick JF, Gard D (1996) Primary oral squamous cell carcinoma: A review of 92 cases. J Oral Maxillofac Surg 54: 949-954.

11. Al Balawi SA, Nwoku AL (2002) Management of oral cancer in a tertiary care hospital. Saudi Med J 23: 156-159.

12. Al Jaber A, Al Nasser L, El Metwally A (2016) Epidemiology of oral cancer in Arab countries. Saudi Med J 37: 249-255.

13. Shah I, Sefvan O, Luqman U, Ibrahim W, Mehmood S, et al. (2010) Clinical stage of oral cancer patients at the time of initial diagnosis. Journal of Ayub Medical College Abbottabad 22: 61-63.

14. Krishna A, Singh RK, Singh S, Verma P, Pal US, et al (2014) Demographic risk factors, affected anatomical sites and clinicopathological profile for oral squamous cell carcinoma in a north Indian population. Asian Pac J Cancer Prev 15: 6755-6760.

15. Su CC, Yang HF, Huang SJ, Lian IB (2007) Distinctive features of oral cancer in Changhua County: High incidence, buccal mucosa preponderance, and a close relation to betel quid chewing habit. J Formos Med Assoc 106: 225-233.

16. Warnakulasuriya $S$ (2009) Global epidemiology of oral and oropharyngeal cancer. Oral Oncol 45: 309-316.

17. Allard WF, DeVol EB, Te OB (1999) Smokeless tobacco (shamma) and oral cancer in Saudi Arabia. Community Dent Oral Epidemiol 27: 398-405.

18. Alsanosy RM (2014) Smokeless tobacco (shammah) in Saudi Arabia: A review of its pattern of use, prevalence, and potential role in oral cancer. Asian Pac J Cancer Prev 15: 6477-6483.

19. Ferlay J, Soerjomataram I, Dikshit R, Eser S, Mathers C, et al. (2015) Cancer incidence and mortality worldwide: Sources, methods and major patterns in GLOBOCAN 2012. Int J Cancer 136: E359-E386.

20. Abdo EN, Garrocho AD, Barbosa AA, Oliveira EL, França Filho L, et al. (2007) Time elapsed between the first symptoms, diagnosis and treatment of oral cancer patients in Belo Horizonte, Brazil. Med Oral Pathol Oral y Cir Bucal 12: 469-473.

21. Brandizzi D, Gandolfo M, Velazco ML, Cabrini RL, Lanfranchi HE (2008) Clinical features and evolution of oral cancer: A study of 274 cases in Buenos Aires, Argentina. Med Oral Patol Oral Cir Bucal 13: E544-E548.

22. de Araújo Júnior RF, Barboza CA, Clebis NK, Adrianne S, de Moura B, et al. (2008) Prognostic significance of the anatomical location and TNM clinical classification in oral squamous cell carcinoma. Med Oral Patol Oral y Cir Bucal 13: E344-E347.

23. Shiboski CH, Schmidt BL, Jordan RC (2007) Racial disparity in stage at diagnosis and survival among adults with oral cancer in the US. Community Dent Oral Epidemiol 35: 233-240.

24. Nemes JA, Redl P, Boda R, Kiss C, Márton IJ (2008) Oral cancer report from Northeastern Hungary. Pathol Oncol Res 14: 85-92.

25. de Camargo Cancela M, Voti L, Guerra Yi M, Chapuis F, Mazuir M, et al. (2010) Oral cavity cancer in developed and in developing countries: Population-based incidence. Head Neck 32: 357-367. 